\title{
Political strategies applied in Romania wind energy market in a medium and long run
}

\author{
Ştefan Ţălu ${ }^{*}$, Anton Nazarov ${ }^{2}$ \\ ${ }^{1}$ Technical University of Cluj-Napoca, Cluj-Napoca, 400020, Cluj county, Romania \\ ${ }^{2}$ Ural State University of Economics, 8 Marta str. 62/45, 620144 Yekaterinburg, Russian Federation
}

\begin{abstract}
This paper analyses the main measures to be adopted in the field of wind energy in the medium and long term in Romania and assesses the progress made by Romania in comparison with the European Union and the objectives set by the Community institutions. The paper aims to identify opportunities for the development of the wind energy sector based on existing resources, which will be a positive factor in generating positive economic and social effects. The study indicates that Romania has a high potential for wind resources, which can be harnessed through appropriate policies to support projects related to this type of energy.
\end{abstract}

\section{Introduction}

International energy markets are in a complex dynamic with difficult challenges exacerbated by the global financial crisis. These challenges have a decisive impact on energy markets at all levels and bear the imprint of a threat to local energy security. International energy markets are evaluated on several dimensions: technological, climatic, geopolitical, and economic [1,2].

The European Commission (EC) energy policies have linked energy security to the European Union (EU) with sustainable development in a strategy with several objectives, among which we list: - achieving and diversifying a complete internal energy market integrated; - the creation of a functional infrastructure and diversification of external energy supply sources; - quantitative and qualitative increase in energy production in the EU; increasing the degree of European regional security, as well as protecting the strategic critical energy infrastructure, by coordinating national energy policies, but also by external energy diplomacy. The EU, through the appropriate mechanisms, finances energy projects, primarily those in the field of "clean energy" and the interconnection of European energy markets [1, 3].

Romania in the current geopolitical context must anticipate and position itself flexibly towards the trends on the international markets to the geopolitical resettlements that decisively influence the strategic partnerships in the region. Romania presents a balanced and diversified energy palette, illustrated by energy-producing companies, each focused on the

\footnotetext{
*Corresponding author: stefan.talu@auto.utcluj.ro
} 
exploitation of a type of primary energy resource, as well as by electricity transmission operators.

Romania currently needs coherent and clean energy policies, as well as pragmatic investments for the growth of the Romanian energy sector. The growth of the Romanian economy from the perspective of the energy sector involves the construction of new energy production capacities; modernization and refurbishment of production capacities; energy transmission and distribution; encouraging the growth of energy-efficient domestic consumption; as well as export [3].

The energy strategy promoted by Romania has clear, well-defined objectives, through which Romania confirms its position as a producer of energy in the region and active factor in national energy management, which will produce substantial changes and will energize the entire energy sector $[4,5]$.

The multiple technological developments have led to the European markets, energy efficiency policies, which have materialized in a slight decrease in energy demand, stimulated by diversification of supply. In Romania, technological development in the energy field has led to relatively high energy prices, largely amortized by subsidies from public budgets, but which have materialized in production increased energy. Through this prism, a decrease in energy production costs was found, in contrast to the accelerated progress of energy consumption management systems [6].

The implementation of IT technologies, through the development and modernization of smart grids with real-time coordination and two-way communication, have led to increased operational capacity for analysis and transmission of large volumes of data, with beneficial implications for optimizing energy consumption. It is found, as with the increase in production decentralized electricity may arise the situation of reorganizing the electricity transmission and distribution system, with the emergence of active consumers and the strengthening of electricity storage capacities.

In the energy sector, climate and environmental policies have a major impact, with the role of reducing pollutant emissions, but also on influencing decisions and social attitudes to choose "clean energy", to model both investment behaviour and consumption patterns. To achieve a sustainable national energy system, by the provisions of the 2015 Paris Agreement, but also of European policies to prevent climate change, it is necessary to implement measures to reduce pollutant emissions in the energy sector, to limit global warming at a maximum of $2{ }^{\circ} \mathrm{C}$ from the pre-industrial level. National energy policy planners have several clear objectives for implementing an optimized, economical energy transition process, including increasing energy efficiency and creating a global set of decarbonization indicators.

In Europe's energy supply crises, regional cooperation is an effective solution as it allows the development of energy markets, but also of specific regional energy security mechanisms, which have specified operating rules within the EU. Currently, Romania has an interconnection capacity of $9.5 \%$, especially with the interconnections with Hungary, Bulgaria, and Serbia; but Romania also aims to develop interconnections with neighbouring countries outside the EU (Republic of Moldova, Ukraine).

The main advantages of wind energy are: - it is zero emission of pollutants and greenhouse gases; - no waste is produced; - low costs per unit of energy produced; - low decommissioning costs at the end of the normal operation period, when practically they can be fully recycled. Among the disadvantages of using wind energy we mention: - visual pollution - that is, they have an unpleasant appearance; - noise pollution; - a practical disadvantage is the variation in wind speed.

Being located at the border of the Balkan Peninsula and covering an elliptical surface of $238,391 \mathrm{~km}^{2}$, Romania is at the eastern limit of the atmospheric circulation generated in the North Atlantic basin, which has a sufficiently high intensity that offers a substantial energy recovery on the ridges of the Carpathian mountains at high altitudes and favourable areas. 
Romania has a temperate continental climate of transition, specific to Central Europe, but with a high energy potential, which is highlighted especially in coastal and coastal areas, but also in alpine areas with plateaus and mountain valleys.

On the other hand, the atmospheric circulation generated in the area of the Black Sea and the Russian Plain, in conjunction with the North Atlantic, lead to real possibilities of advantageous energy recovery in the areas of Dobrogea, Bărăgan, and Moldova. Also, in small areas, there are local atmospheric circulations that allow the construction of small wind farms for efficient economic recovery.

Romania has the greatest potential in South-Eastern Europe in the field of wind energy, and the position of South-Eastern Dobrogea is among the first places on the European continent. Wind turbines start from a wind speed of only $3.5 \mathrm{~m} / \mathrm{s}$, but in Dobrogea the measurements showed that the speed is $7 \mathrm{~m} / \mathrm{s}$ at a height of 100 meters.

Table 1. Wind power installed capacity in Romania in MW in period 2009-2019

\begin{tabular}{|l|l|l|l|l|l|l|l|l|l|l|}
\hline Year & 2010 & 2011 & 2012 & 2013 & 2014 & 2015 & 2016 & 2017 & 2018 & 2019 \\
\hline MW & 389 & 988 & 1.822 & 2,773 & 3,244 & 3,130 & 3,025 & 3,030 & 3,032 & 3,040 \\
\hline
\end{tabular}

Hidroelectrica, the main producer in the Romanian energy industry, has proposed in its investment agenda a series of onshore and offshore wind projects, each of $300 \mathrm{MW}$, to be completed in 2025 and 2026, respectively, through an investment of 26 billion lei, of which almost 7.6 billion in the period 2020-2025. This investment project is the first in Romania, as, at present, there are no offshore wind farms installed in the Romanian Black Sea sector.

The production of energy from offshore wind sources has some important advantages, among which we list: a large number of operating hours with low variability, which implies low forecast errors and low balancing costs compared to onshore wind energy. The offshore wind potential allows investments in production and consumption capacities of "green hydrogen", but also the creation of national industrial entities in the field of offshore wind energy and hydrogen, with a positive impact on the creation of new jobs nationwide.

\section{Research methodology}

In this study, one question was proposed: What are the appropriate policies that can be applied in Romania, in the wind industry, in the medium and long term to improve the developments in the field of wind energy depending on regional conditions, stimulated by the national regulatory framework?

\section{Discussions}

The directions of action proposed in wind energy in Romania to be implemented on a medium and long term at a national level are: - increasing the number of auctions and facilitating them to increase the production capacity of electricity from wind energy; simplification of administrative procedures; - promoting investments in infrastructure and network interconnections. The volatility of energy production in wind farms in Romania requires the entire national energy system, which requires a reassessment of the need for system services and appropriate investments in state-of-the-art power plants, with modern, fast control, and efficient storage systems.

From the analysis of the decisive political factors in Romania regarding wind energy on a medium and long term, several conclusions can be drawn: 
- obtaining wind energy is still dependent on public support and folds after major political changes on the political scene;

- there is a lack of a clear, well-defined plan, which due to hasty regulations, without an adequate impact study and by avoiding consulting all actors involved in the wind energy market has led to low distrust of producers in the field, who have not invested capital enough on this segment;

- the existence of high risks, but also of a long-term investment return;

- adoption of advanced technologies in the sector wind energy, by attracting private investment, through supporting scientific research and development strategic partnerships;

- developing cooperation in the field of research scientific studies in the wind energy sector and the transfer of know-how;

- cooperation with the authorities of the partner states for increase infrastructure security [7];

- increasing the management of wind energy companies with state capital in order to increase their value on the medium and long term;

- economic optimization of the assets and investment projects of wind energy companies;

- eliminating bureaucracy through transparency and digitization;

- developing institutional mechanisms by publishing regular reports on public procurement and all sponsorships granted;

- settling and eliminating conflicts of interest between institutions public and state-owned energy companies;

- supporting scientific research, technological development and innovation in the field of wind energy, by participating in international consortia;

- organizing information programs and public debates on major wind energy projects, taking into account the interests of local communities, but also the national interest;

- the development of partnerships with the universities with the wind energy industry, as well as of the research - development - innovation institutes [8-10];

- implementation of physical security measures for critical infrastructure against possible malicious actions; - computer security of energy network control systems by increasing the degree of protection; - attracting European and international funding sources for scientific research in the field.

\section{Conclusions}

This article proposed a series of local political measures that can be applied in the context of wind energy in Romania to be implemented on a medium and long term at a national level.

The paper identified opportunities for the development of the wind energy sector based on existing resources, which will be a positive factor in generating positive economic and social effects. All in all, our results indicated that Romania has a high potential for wind resources, which can be harnessed through appropriate policies to support projects related to this type of energy.

\section{References}

1. Romanian energy strategy 2016-2030, with an outlook to 2050, Ministry of Energy, http://energie.gov.ro/ (2021)

2. Romania wind energy market (2020-2025), https://www.mordorintelligence.com/ (2021)

3. M.I. Aceleanu, A.C. Șerban, D.M. Pociovălișteanu, G.C. Dimian, Energy Sources, Part B: Economics, Planning, and Policy, 12, 958 (2017) 
4. F. Onea, E. Rusu, Energy Explor. Exploit., 34, 217 (2016)

5. F. Onea, L. Rusu. J. Mar. Sci. Eng., 7, 142 (2019)

6. N Marinescu, Energies, 13, 6493 (2020)

7. Ș. Țălu, Advances in Economics, Business and Management Research (AEBMR), 156, $522(2020)$

8. Ș. Ţălu, Advances in Economics, Business and Management Research (AEBMR), 105, 554 (2019)

9. Ș. Ţălu, Advances in Economics, Business and Management Research (AEBMR), 138, 253 (2020)

10. Ș. Țălu, A. Nazarov, E3S Web of Conferences, 208, 09005, 1-6 (2020) 